\title{
Plant-mediated links between detritivores and aboveground herbivores
}

\author{
Susanne Wurst* \\ Dahlem Centre of Plant Sciences, Functional Biodiversity, Freie Universität Berlin, Berlin, Germany
}

\section{Edited by:}

Sergio Rasmann, University of

California Irvine, USA

Reviewed by:

Roxina Soler, Wageningen University, Netherlands

Mary Beth Mudgett, Stanford

University, USA

*Correspondence:

Susanne Wurst, Dahlem Centre of Plant Sciences, Functional

Biodiversity, Freie Universität Berlin, Königin-Luise-Strasse 1-3, 14195

Berlin, Germany

e-mail: s.wurst@fu-berlin.de
Most studies on plant-mediated above-belowground interactions focus on soil biota with direct trophic links to plant roots such as root herbivores, pathogens, and symbionts. Detritivorous soil fauna, though ubiquitous and present in high abundances and biomasses in soil, are under-represented in those studies. Understanding of their impact on plants is mainly restricted to growth and nutrient uptake parameters. Detritivores have been shown to affect secondary metabolites and defense gene expression in aboveground parts of plants, with potential impacts on aboveground plant-herbivore interactions. The proposed mechanisms range from nutrient mobilization effects and impacts on soil microorganisms to defense induction by passive or active ingestion of roots. Since their negative effects (disruption or direct feeding of roots) may be counterbalanced by their overall beneficial effects (nutrient mobilization), detritivores may not harm, but rather enable plants to respond to aboveground herbivore attacks in a more efficient way. Both more mechanistic and holistic approaches are needed to better understand the involvement of detritivores in plant-mediated above-belowground interactions and their potential for sustainable agriculture.

Keywords: above-belowground interactions, earthworms, Collembola, microorganisms, herbivores, defense, priming

\section{INTRODUCTION}

Links between the below- and the aboveground compartments of terrestrial ecosystem have been the focus of a growing number of studies in the last two decades. Integrating the two compartments is crucial for a better understanding of the ecology, function, and evolution of terrestrial ecosystems. In the first review articles on plant-mediated effects of soil biota on aboveground herbivores (Scheu and Setälä, 2001; Scheu and Setälä, 2001; Wardle et al., 2004) soil organisms were divided in two groups, either with or without direct trophic links to the plant. The majority of studies and reviews that have followed focused on soil biota with direct trophic interaction to plant roots such as root herbivores, pathogens, and arbuscular mycorrhizal fungi (reviewed by, e.g., Bezemer and van Dam, 2005; Koricheva et al., 2009; van Dam and Heil, 2011; Johnson et al., 2012). Soil organisms in indirect interaction with roots, such as members of the decomposer subsystem, have received far less attention (but see Wurst, 2010). This is surprising, since detritivores are ubiquitous and very abundant in soil, play a crucial role in nutrient turnover and decomposition processes, and can have profound effects on plant and herbivore performance mediated by different mechanisms.

In this review, I focus on plant-mediated links between detritivorous soil fauna and aboveground herbivores. With earlier reviews having focused mainly on soil biota with direct trophic links to plant roots, this review specifically deals with soil biota in indirect interaction with roots. First, I give a short summary of the reported impacts of detritivores on aboveground herbivores (see PlantMediated Effects of Detritivores on Aboveground Herbivores).
Then I present investigated and proposed mechanisms behind the observed effects (see Mechanisms of How Detritivores Affect Plant and Aboveground Herbivore Performance), before comparing the mechanisms involved in the effects of soil biota in indirect interaction vs. direct interaction with roots (see Mechanisms Involved in the Effects of Soil Biota in Direct and Indirect Interaction with Roots). Finally, I highlight promising avenues for future research (see Research Perspectives). With this review, I hope to place detritivores "in the spot light," because their rather neglected role in studies on plant-mediated interactions between soil biota and aboveground herbivores and their antagonists does not reflect their importance in below-aboveground links of terrestrial ecosystems.

\section{PLANT-MEDIATED EFFECTS OF DETRITIVORES ON ABOVEGROUND HERBIVORES}

One of the first studies of plant-mediated effects of detritivores on aboveground herbivores was carried out on collembolans and earthworms (Scheu et al., 1999). The effects of Collembola (Heteromurus nitidus and Onychiurus scotarius) and endogeic earthworms (Aporrectodea caliginosa and Octolasion tyrtaeum) on growth of a grass (Poa annua) and a legume (Trifolium repens), and on aphid (Myzus persicae) reproduction on their leaves were investigated. Besides effects on plant growth, Collembola had strong effects on aphid reproduction that differed in direction and magnitude between the different plant species. On average, aphid reproduction was decreased by $45 \%$ on $T$. repens, but transiently increased ca. threefold on Poa annua in presence of Collembola. Earthworms had a strong positive, 
but also transient effect on aphid reproduction on both plant species. Subsequent studies investigated the impacts of earthworms (Bonkowski et al., 2001; Wurst and Jones, 2003; Wurst et al., 2003, 2004a,b; Newington et al., 2004; Poveda et al., 2005; Eisenhauer et al., 2010; Wurst and Forstreuter, 2010; Johnson et al., 2011) and Collembola (Haase et al., 2008; Ke and Scheu, 2008; Schütz et al., 2008) on aboveground herbivores. In the majority of studies, the impact of earthworms and Collembola was investigated on aboveground phloem-feeding aphids. As far as we are aware, only one study (Newington et al., 2004) investigated the plant-mediated effects of earthworms on a leaf-chewing caterpillar (Mamestra brassicae). When considering also studies on the impact of detritivores on plant communities, two studies, as far as we are aware, investigated the effects of earthworms on herbivorous snails (Thompson et al., 1993; Wurst and Rillig, 2011). Thus, the majority of studies focused on one feeding type of aboveground herbivores (phloem-feeders), and earthworms and Collembola as detritivores.

The plant-mediated effects of detritivores on aboveground herbivores vary in strength and direction. The impacts of earthworms on above- and belowground herbivores have been reviewed before (Wurst, 2010). In short, their plant-mediated effects on aboveground herbivores range from negative, neutral to positive, and may depend on soil characteristics such as soil nutrient content, distribution of soil organic matter, and the soil microbial community. The effects of Collembola on aphids also range from negative through neutral to positive and were suggested to differ in direction between more and less palatable plant species (Scheu et al., 1999) and to be affected by fertilizer addition (Schütz et al., 2008).

Thus the effects of detritivores on plant-herbivore interactions are highly context dependent and are influenced by soil and plant characteristics. Overall, it is important to note that the effects of the detritivores on aboveground herbivores are not always positive and related to an enhanced nutrient availability for the plants, but can also be negative suggesting other mechanisms besides nutrient mobilization. Mechanisms by which detritivores may affect plant and herbivore performance are discussed in the next section.

\section{MECHANISMS OF HOW DETRITIVORES AFFECT PLANT AND ABOVEGROUND HERBIVORE PERFORMANCE}

Soil organisms of the decomposer subsystem (Wardle et al., 2004) are responsible for important ecological processes such as litter incorporation, litter fragmentation, nutrient mineralization and immobilization which affect the nutrient availability for plants with consequences for herbivore performance. These processes are interactively performed by functionally different soil organisms belonging to a variety of size classes, ranging from microbes to macrofauna (Bardgett, 2005; Wurst et al., 2012). Thus, effects of detritivorous soil organisms on plant and aboveground herbivore performance are often mediated by their impacts on nutrient turnover and decomposition processes. Other proposed mechanisms for their effects involve grazing on soil biota in direct interaction with plants (e.g., mycorrhizal fungi and root pathogens), dispersal of microorganisms, changes of soil structure and hormone-like effects (reviewed by Scheu and Setälä, 2001; Scheu and Setälä, 2001). All these processes can affect nutrient availability and growth of plants with consequences on aboveground herbivores.

It has, however, also been shown that detritivorous soil organisms can affect defense compounds in plants and the expression of defense-related genes. It has been documented that earthworms can reduce aphid reproduction (Wurst et al., 2003) and that this may be related to changes in plant defense compounds induced by earthworms (Wurst et al., 2004a,b). Earthworms enhanced the concentration of phytosterols, but this effect was influenced by the litter distribution in soil (Wurst et al., 2004a), and decreased the concentration of the iridoid glycoside catapol in leaves of Plantago lanceolata (Wurst et al., 2004b). Both compounds play an important role for herbivore performance; phytosterols are precursors of molting hormones, while iridoid glycosides are secondary metabolites known to deter generalist insect herbivores and pathogens. Additionally, effects of earthworms on the N-based secondary metabolites glucosinolates in Brassicaceae were documented; however, the effects varied between different groups of glucosinolates. While sulfurcontaining glucosinolates were reduced by earthworms in Brassica oleracea leaves (Wurst et al., 2006), aliphatic glucosinolates were reduced and aromatic glucosinolates were enhanced in Sinapis alba (Lohmann etal., 2009). Blouin et al. (2005) showed that earthworms can change stress-responsive gene expression (such as genes coding for lipoxygenase and cysteine protease) and make rice (Oryza sativa) plants more resistant to root-feeding nematodes.

Recently, it has been documented that earthworms influence the expression of genes involved in cell proliferation and stress response in the model plant Arabidopsis thaliana (Jana et al., 2010). Puga-Freitas et al. (2012) proposed that signal molecules (such as indole acetic acid, IAA) may mediate the earthworm effects on plant growth. They also showed that earthworms change the expression of genes responsive to abiotic and biotic stress, and to the application of exogenous hormones. Since the plant responses to earthworms resembled responses known to occur in the systemic resistance induced by plant growth promoting rhizobacteria (PGPR; induced systemic resistance, ISR) and/or pathogens (systemic acquired resistance, SAR), the latter authors and Wurst (2010) proposed that earthworm effects on plant resistance may be mediated by changes in abundance or activity of rhizosphere microorganisms such as PGPR. In summary, experimental studies document that earthworms systemically affect secondary metabolites and the expression of stress-related genes in different plant species which may mediate their effect on aboveground herbivore performance.

For Collembola, it has been recently reported that they also have the ability to affect the expression of defense-related and auxin-responsive genes (Endlweber et al., 2011). The latter authors therefore suggested that Collembola improve plant resistance against herbivores by enhancing the production of secondary compounds while concomitantly compensating the production costs by fostering root growth and nutrient exploitation.

This duality of impact on plant growth and defense may be a characteristic feature of the impact of detritivores on plants (Figure 1). As well as enhancing nutrient availability for the plants, they also induce stress-responsive genes and systemically change 


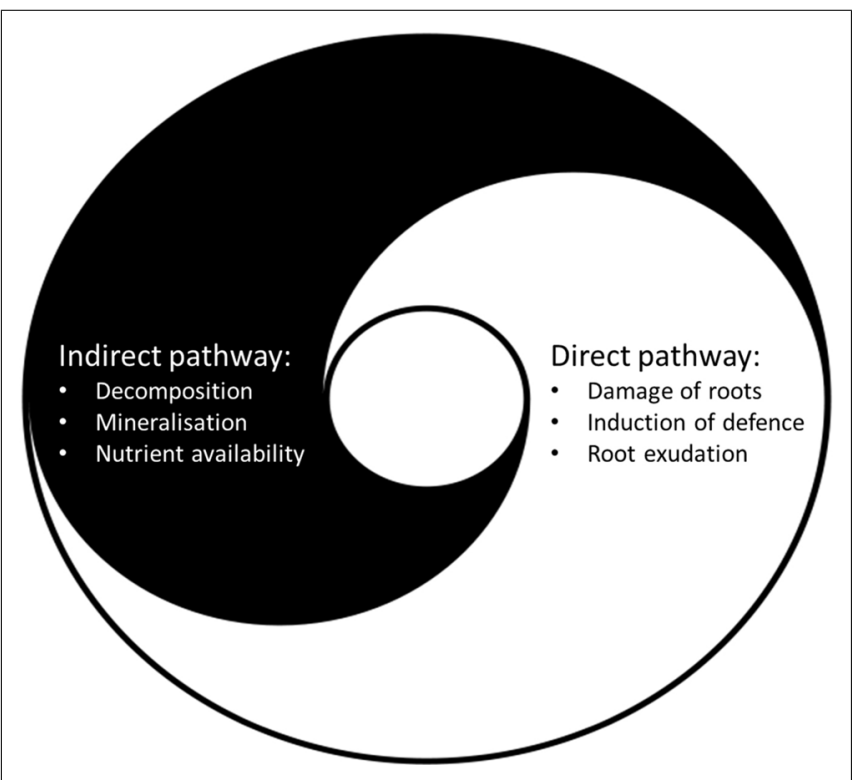

FIGURE 1 | The indirect and the direct pathway to plants are intimately linked and many soil biota affect both pathways. Soil biota in indirect interaction with roots (e.g., detritivores) enhance nutrient availability by promoting decomposition and mineralization processes (indirect pathway), but also damage roots which may lead to induction of defense and root exudation (direct pathway). Soil biota in direct trophic interaction with roots (e.g., insect root herbivores) feed and damage roots, induce defense, and change root exudation (direct pathway) which may lead to enhanced microbial activity, mineralization, and nutrient availability (indirect pathway) [image: modified from Christian Hummert (Ixitixel)].

the production of secondary metabolites in the plants. Since their beneficial effects (nutrient mobilization) may counterbalance their negative effects (disruption or direct feeding of roots), detritivores may not harm, but rather prepare plants to respond to aboveground herbivore attacks in a more efficient way. This issue is further developed in Section "Research Perspectives" regarding future research perspectives.

\section{MECHANISMS INVOLVED IN THE EFFECTS OF SOIL BIOTA IN DIRECT AND INDIRECT INTERACTION WITH ROOTS}

The impact on shoot herbivores by soil biota with a direct trophic link to the plant can be mediated by changes in water and nutrient uptake and/or an induction of plant defense that affects the whole plant systemically (reviewed by van Dam et al., 2003; Bezemer and van Dam, 2005; Koricheva et al., 2009; van Dam and Heil, 2011; Johnson et al., 2012). The same seems to be true for soil biota in indirect interaction to plants as summarized above for detritivores such as earthworms and Collembola. Interestingly, the Collembola Protaphorura fimata has been reported to act as a root herbivore and may predominately feed on roots (Endlweber et al., 2009). Other well-known detritivores, the crustacean isopods Porcellio scaber and Armadillidium vulgare, can become herbivores on jasmonate-deficient plants (Farmer and Dubugnon, 2009). A recent study reported that the anecic earthworm Lumbricus terrestris can act as a shoot herbivore (Griffith et al., 2013). These studies demonstrate that detritivorous soil biota may be more omnivorous than previously thought and that living plant material might be a substantial part of their diet. Besides the challenge to classify soil biota into distinct feeding guilds, the interaction of soil biota with plants generally has both a direct and indirect component. For example, feeding by root herbivores may induce plant defense and root exudation (direct pathway) leading to a stimulation of the microbial activity and mineralization processes (indirect pathway) (Bardgett et al., 1999; Dawson et al., 2004). Thus soil biota in direct trophic interaction also change indirect pathways to plants. On the other hand, soil biota with mainly indirect non-trophic interaction to plants may affect soil biota in direct interaction with roots, disturb the root system and thus also affect the direct pathway to plants (Figure 1). The relative contribution of soil biota to the indirect and the direct pathway may also change with conditions, such as the abundance and quality of roots, the microbial community and the nutrient availability in soil.

\section{RESEARCH PERSPECTIVES}

Our knowledge on effects of detritivores on plant-herbivore interactions above the ground are almost exclusively based on earthworms and collembolan studies. Other detritivorous soil fauna belonging to taxonomic groups such as isopoda, diplopoda, or insects have been not or very rarely considered. GonzálezMegías and Müller (2010) investigated the effects of a detritivorous beetle larvae (Morica hybrida, Tenebrionidae) in interaction with a belowground herbivorous beetle larvae (Cebrio gypsicola, Cebrionidae) and aboveground herbivores on Moricandia moricandioides (Brassicaceae) and aboveground higher trophic levels in the field. They reported effects of detritivores up to the third trophic level above the ground: parasitoid attack rate and abundance were positively affected by the presence of detritivores. This is one of the few studies (Wurst and Jones, 2003; Poveda et al., 2005; GonzálezMegías and Müller, 2010; Johnson et al., 2011) that followed the effects of detritivores up to the third level, i.e., the antagonists of herbivores above the ground. The results show that detritivores cannot only change direct defense of plants against herbivores, but may influence indirect defense mechanisms such as the recruitment of herbivore antagonists. As far as I am aware, there are no studies on the impacts of isopoda and diplopoda on plantherbivore interactions and direct or indirect plant defense above the ground. In general, studies with different detritivore taxa and more field studies are needed to better judge the plant-mediated impact of detritivores on higher trophic levels and indirect plant defense mechanisms.

Besides the claim for a more holistic approach that involves also studying higher trophic levels under natural conditions, it is important to further elucidate the underlying mechanisms of plant-mediated interactions between detritivores, aboveground herbivores, and their antagonists. Here, it is promising to ask whether detritivores can prime plants to better cope with stresses. Priming of plants for a more efficient activation of defense responses has been documented for PGPR (Pieterse et al., 2003; Conrath et al., 2006; van Loon, 2007). By inducing stressresponsive genes and counterbalancing the costs through an enhanced nutrient mobilization and availability for the plants, detritivores may also prime plants to be better prepared for abiotic and biotic stresses. They may do this either directly or mediated 
by changes in the soil microbial community, e.g., the abundance of PGPR (Wurst, 2010). All this is so far unknown, but waits to be explored in future research that may also contribute to the development of more sustainable plant protection strategies.

In summary, I propose two promising approaches for future research based on the described knowledge gaps and the potential importance of detritivores for plant-mediated abovebelowground interactions: on the one hand, more holistic approaches including different detritivorous taxa studied under (semi-) natural conditions to determine their plant-mediated impacts on herbivores and their antagonists in natural and agricultural systems; on the other hand, more mechanistic studies

\section{REFERENCES}

Bardgett, R. D. (2005). The Biology of Soil. A Community and Ecosystem Approach. Oxford: Oxford University Press. doi: 10.1093/acprof:oso/97801 98525035.001.0001

Bardgett, R. D., Denton, C. S., and Cook, R. (1999). Below-ground herbivory promotes soil nutrient transfer and root growth in grassland. Ecol. Lett. 2, 357-360. doi: 10.1046/j.14610248.1999.00001.x

Bezemer, T. M., and van Dam, N. M. (2005). Linking aboveground and belowground interactions via induced plant defenses. Trends Ecol. Evol. 20, 617-624. doi: 10.1016/j.tree.2005.08.006

Blouin, M., Zuily-Fodil, Y., Pham-Thi, A. T., Laffray, D., Reversat, G., Pando, A., et al. (2005). Belowground organism activities affect plant aboveground phenotype, inducing plant tolerance to parasites. Ecol. Lett. 8, 202-208. doi: 10.1111/j.14610248.2004.00711.x

Bonkowski, M., Geoghegan, I. E., Birch, A. N. E., and Griffiths, B. S. (2001). Effects of soil decomposer invertebrates (protozoa and earthworms) on an aboveground phytophagous insect (cereal aphid) mediated through changes in the host plant. Oikos 95, 441450. doi: 10.1034/j.1600-0706.2001. 950309.x

Conrath, U., Beckers, G. J. M., Flors, V., Garcia-Agustin, P., Jakab, G., Mauch, F., et al. (2006). Priming: getting ready for battle. Mol. Plant Microbe Interact. 19, 1062-1071. doi: 10.1094/MPMI-19-1062

Dawson, L. A., Grayston, S. J., Murray, P. J., Ross, J. M., Reid, E. J., and Treonis, A. M. (2004). Impact of Tipula paludosa larvae on plant growth and the soil microbial community. Appl. Soil Ecol. 25, 51-61. doi: 10.1016/S09291393(03)00099-4

Eisenhauer, N., Hoersch, V., Moeser, J., and Scheu, S. (2010). Synergistic effects of microbial and animal decomposers on plant and herbivore performance. Basic Appl. Ecol. 11, 23-34. doi: 10.1016/j.baae.2009. 11.001

Endlweber, K., Krome, K., Welzl, G., Schaeffner, A. R., and Scheu, S. (2011). Decomposer animals induce differential expression of defence and auxin-responsive genes in plants. Soil Biol. Biochem. 43, 1130-1138. doi: 10.1016/j.soilbio.2010.11.013

Endlweber, K., Ruess, L., and Scheu, S. (2009). Collembola switch diet in presence of plant roots thereby functioning as herbivores. Soil Biol. Biochem. 41, 11511154. doi: 10.1016/j.soilbio.2009. 02.022

Farmer, E. E., and Dubugnon, L. (2009). Detritivorous crustaceans become herbivores on jasmonatedeficient plants. Proc. Natl. Acad. Sci. U.S.A. 106, 935-940. doi: 10.1073/pnas.0812182106

González-Megías, A., and Müller, C. (2010). Root herbivores and detritivores shape aboveground multitrophic assemblage through plantmediated effects. J. Anim. Ecol. 79, 923-931. doi: 10.1111/j.13652656.2010.01681.x

Griffith, B., Tuerke, M., Weisser, W. W., and Eisenhauer, N. (2013). Herbivore behavior in the anecic earthworm species Lumbricus terrestris L.? Eur. J. Soil Biol. 55, 62-65. doi: 10.1016/j.ejsobi.2012. 12.002

Haase, J., Brandl, R., Scheu, S., and Schaedler, M. (2008). Above- and belowground interactions are mediated by nutrient availability. Ecology 89, 3072-3081. doi: 10.1890/071983.1

Jana, U., Barot, S., Blouin, M., Lavelle, P., Laffray, D., and Repellin, A. (2010). Earthworms influence the production of aboveand belowground biomass and the expression of genes involved in cell proliferation and stress responses in Arabidopsis thaliana.

addressing the underlying mechanisms with special emphasis on effects of detritivores on plant physiology and defense pathways. Both approaches combined will help to better understand the impact of detritivores on aboveground plant herbivore interactions and to evaluate their potential for improving crop yield and herbivore resistance in sustainable agriculture.

\section{ACKNOWLEDGMENTS}

Thanks to Dr. Ilja Sonnemann for comments on a previous version of the manuscript. The mini-review was funded by The German Science Foundation (DFG), CRC 973 "Priming and memory of organismic responses to stress."

Soil Biol. Biochem. 42, 244-252. doi: 10.1016/j.soilbio.2009.10.022

Johnson, S. N., Clark, K. E., Hartley, S. E., Jones, T. H., McKenzie, S. W., and Koricheva, J. (2012). Abovegroundbelowground herbivore interactions: a meta-analysis. Ecology 93, 22082215. doi: 10.1890/11-2272.1

Johnson, S. N., Staley, J. T., McLeod, F. A. L., and Hartley, S. E. (2011). Plantmediated effects of soil invertebrates and summer drought on aboveground multitrophic interactions. $J$. Ecol. 99, 57-65. doi: 10.1111/j.13652745.2010.01748.x

Ke, X., and Scheu, S. (2008). Earthworms, Collembola and residue management change wheat (Triticum aestivum) and herbivore pest performance (Aphidina: Rhophalosiphum padi). Oecologia 157, 603-617. doi: 10.1007/s00442 008-1106-y

Koricheva, J., Gange, A. C., and Jones, T. (2009). Effects of mycorrhizal fungi on insect herbivores: a metaanalysis. Ecology 90, 2088-2097. doi 10.1890/08-1555.1

Lohmann, M., Scheu, S., and Mueller, C. (2009). Decomposers and root feeders interactively affect plant defence in Sinapis alba. Oecologia 160, 289-298. doi: 10.1007/s00442-0091306-0

Newington, J. E., Setala, H., Bezemer, T. M., and Jones, T. H. (2004). Potential effects of earthworms on leaf-chewer performance. Funct. Ecol. 18, 746-751. doi: 10.1111/j.02698463.2004.00888.x

Pieterse, C. M. J., Van Pelt, J. A., Verhagen, B. W. M., Ton, J., Van Wees, S. C. M., Leon-Kloosterziel, K. M., et al. (2003). Induced systemic resistance by plant growth-promoting rhizobacteria. Symbiosis 35 39-54.

Poveda, K., Steffan-Dewenter, I., Scheu, S., and Tscharntke, T. (2005). Effect of decomposers and herbivores on plant performance and aboveground plant-insect interactions. Oikos 108,
503-510. doi: 10.1111/j.0030-1299. 2005.13664.X

Puga-Freitas, R., Barot, S., Taconnat, L., Renou, J.-P., and Blouin, M. (2012). Signal molecules mediate the impact of the earthworm Aporrectodea caliginosa on growth, development and defence of the plant Arabidopsis thaliana. PLoS ONE 7:e49504. doi: 10.1371/journal.pone. 0049504

Scheu, S. (2001). Plants and generalist predators as links between the below-ground and aboveground system. Basic Appl. Ecol. 2, 3-13. doi: 10.1078/1439-179100031

Scheu, S., and Setälä, H. (2001). "Multitrophic interactions in decomposer food-webs," in Multitrophic Level Interactions, eds T. Tscharntke, and A. H. Bradford (Cambridge: Cambridge University Press), 223-264.

Scheu, S., Theenhaus, A., and Jones, T. H. (1999). Links between the detritivore and the herbivore system: effects of earthworms and Collembola on plant growth and aphid development. Oecologia 119, 541-551. doi: 10.1007/ s004420050817

Schütz, K., Nagel, P., Dill, A., and Scheu, S. (2008). Structure and functioning of earthworm communities in woodland flooding systems used for drinking water production. Appl. Soil Ecol. 39, 342-351. doi: 10.1016/j.apsoil.2008. 02.002

Thompson, L., Thomas, C. D., Radley, J. M. A., Williamson, S., and Lawton, J. H. (1993). The effect of earthworms and snails in a simple plant community. Oecologia 95 171-178. doi: 10.1007/BF00323487

van Dam, N. M., Harvey, J. A., Wackers, F. L., Bezemer, T. M., van der Putten, W. H., and Vet, L. E. M. (2003). Interactions between aboveground and belowground induced responses against phytophages. Basic Appl. Ecol. 4, 63-77. doi: 10.1078/1439-179100133 
van Dam, N. M., and Heil, M. (2011). Multitrophic interactions below and above ground: en route to the next level. J. Ecol. 99, 77-88. doi: 10.1111/j.1365-2745.2010.01761.x

van Loon, L. C. (2007). Plant responses to plant growth-promoting rhizobacteria. Eur. J. Plant Pathol. 119, 243 254. doi: 10.1007/s10658-007-9165-1

Wardle, D. A., Bardgett, R. D., Klironomos, J. N., Setala, H., van der Putten, W. H., and Wall, D. H. (2004). Ecological linkages between aboveground and belowground biota. Science 304, 1629 1633. doi: 10.1126/science. 1094875

Wurst, S. (2010). Effects of earthworms on above- and belowground herbivores. Appl. Soil Ecol. 45, 123-130. doi: 10.1016/j.apsoil.2010. 04.005

Wurst, S., De Deyn, G. B., and Orwin, K. (2012). "Soil Biodiversity and Functions", in Soil Ecology and Ecosystem Services, ed. D. H. Wall (Oxford: Oxford University Press), 28-45.
Wurst, S., Dugassa-Gobena, D. and Scheu, S. (2004a). Earthworms and litter distribution affect plant-defensive chemistry. J. Chem. Ecol. 30, 691-701. doi: $10.1023 /$ B:JOEC.0000028425. 43869.b8

Wurst, S., Dugassa-Gobena, D., Langel, R., Bonkowski, M., and Scheu, S. (2004b). Combined effects of earthworms and vesiculararbuscular mycorrhizas on plant and aphid performance. New Phytol. 163, 169-176. doi: 10.1111/j.14698137.2004.01106.x

Wurst, S., and Forstreuter, M. (2010) Colonization of Tanacetum vulgare by aphids is reduced by earthworms. Entomol. Exp. Appl. 137, 86-92. doi: 10.1111/j.1570-7458.2010.01035.x

Wurst, S., and Jones, T. H. (2003). Indirect effects of earthworms (Aporrectodea caliginosa) on an above-ground tritrophic interaction. Pedobiologia 47, 91-97. doi: 10.1078/0031-405600173
Wurst, S., Langel, R., Reineking, A., Bonkowski, M., and Scheu, S. (2003). Effects of earthworms and organic litter distribution on plant performance and aphid reproduction. Oecologia 137, 90-96. doi: 10.1007/s00442-0031329-x

Wurst, S., Langel, R., Rodger, S., and Scheu, S. (2006). Effects of belowground biota on primary and secondary metabolites in Brassica oleracea. Chemoecology 16, 69-73. doi: 10.1007/s00049-0050328-2

Wurst, S., and Rillig, M. C. (2011) Additive effects of functionally dissimilar above- and belowground organisms on a grassland plant community. J. Plant Ecol. 4, 221-227. doi: 10.1093/jpe/ rtr012

Conflict of Interest Statement: The author declares that the research was conducted in the absence of any commercial or financial relationships that could be construed as a potential conflict of interest.

Received: 30 April 2013; accepted: 21 August 2013; published online: 24 September 2013.

Citation: Wurst S (2013) Plant-mediated links between detritivores and aboveground herbivores. Front. Plant Sci. 4:380. doi: 10.3389/fpls.2013.00380

This article was submitted to PlantMicrobe Interaction, a section of the journal Frontiers in Plant Science.

Copyright (C) 2013 Wurst. This is an open-access article distributed under the terms of the Creative Commons Attribution License (CC BY). The use, distribution or reproduction in other forums is permitted, provided the original author(s) or licensor are credited and that the original publication in this journal is cited, in accordance with accepted academic practice. No use, distribution or reproduction is permitted which does not comply with these terms. 